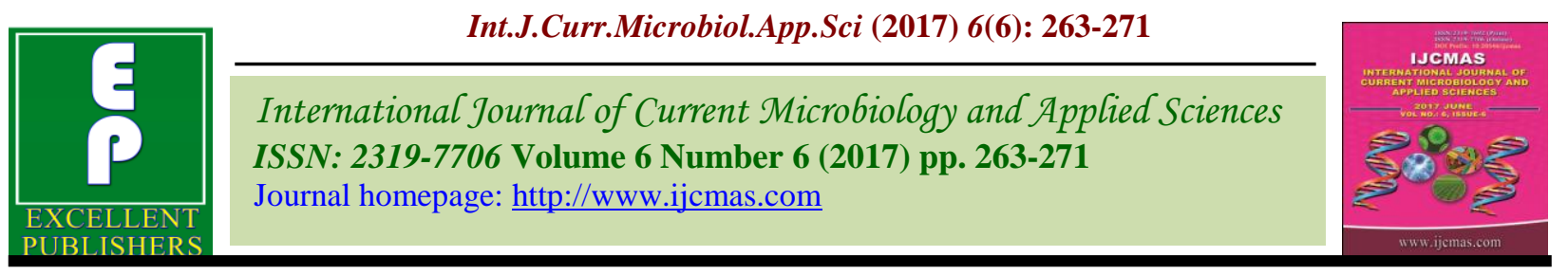

Original Research Article https://doi.org/10.20546/ijcmas.2017.606.032

\title{
Production and Optimization of Amylase from Bacillus cereus Using Submerged Fermentation
}

\author{
Nisha Kumari $^{1,2}$, Veena Jain, Kamla Malik ${ }^{3 *}$ and Sushil ${ }^{2}$ \\ ${ }^{1}$ Oil Seed Section, Department of Genetics and Plant Breeding, College of Agriculture, CCS \\ Haryana Agricultural University, Hisar-125004, Haryana, India \\ ${ }^{2}$ Department of Chemistry and Biochemistry, ${ }^{3}$ Department of Microbiology, College of Basic \\ Sciences and Humanities, CCS Haryana Agricultural University, Hisar-125004, Haryana, India \\ *Corresponding author
}

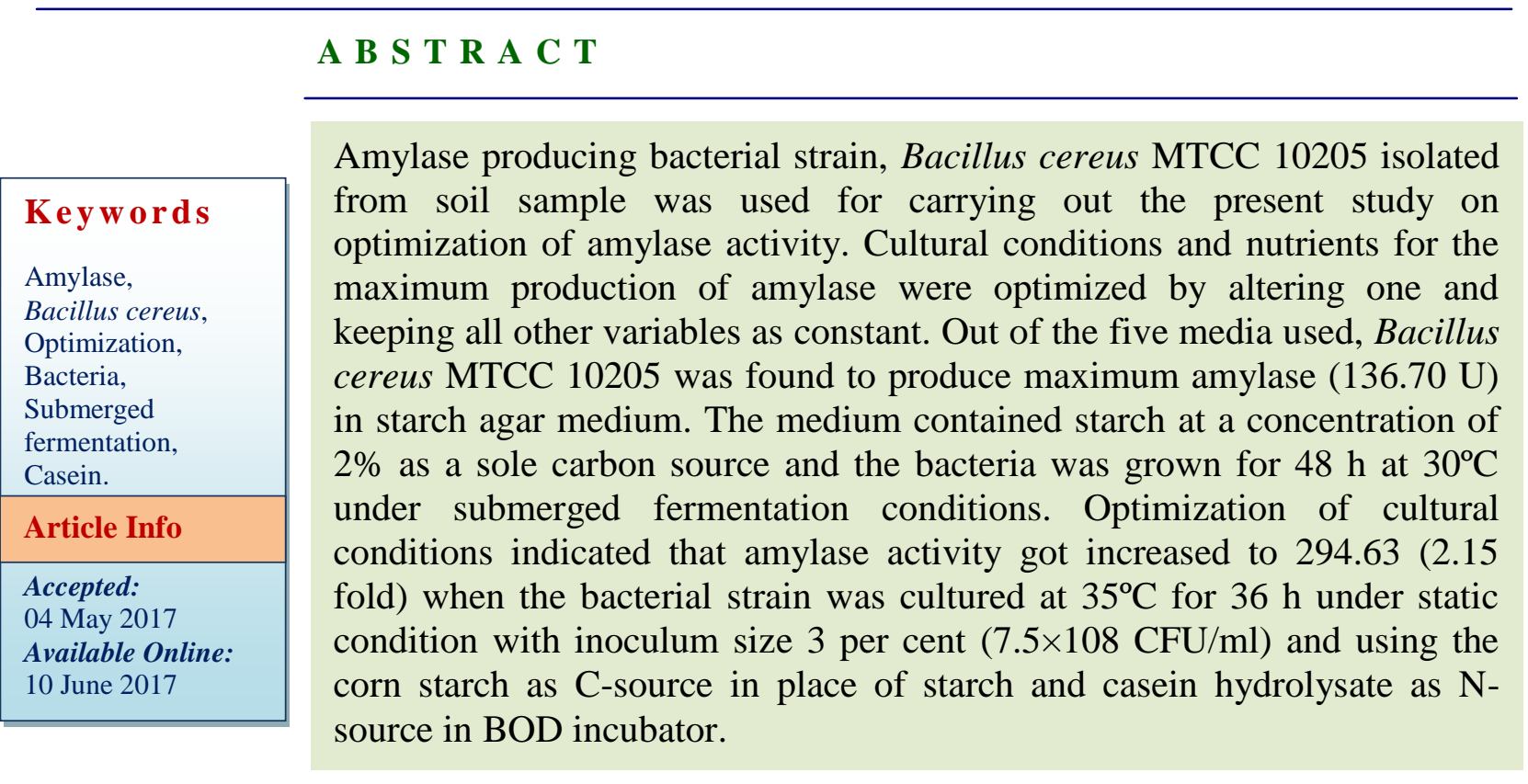

\section{Introduction}

Amylase is one of the most important enzymes in various industries, that catalyses the breakdown of starch into sugar. It can be derived from several sources such as plants, animals and microbes (Rao et al., 2006). Among microbial, plant and animal enzymes, microbial amylases have immense applications in various fields in world market because of their wide application in starch based industries especially food, paper, textile, baking, detergent, pharmaceutical industries etc. (Anupama and Jayaraman, 2011). The major advantage of using microorganisms for the enzyme production is that the process is economically viable and microbes are easy to manipulate to obtain enzymes of desired characteristics (Aiyer, 2005). However, microbial sources are the most preferred one for large scale production meeting industrial demands. Amylases are of ubiquitous occurrence and holding maximum market share of enzyme sales 
(Sivaramakrishanan et al., 2006). Amylases were produced by number of microorganisms such as Bacillus subtilis (El-Banna et al., 2007), Bacillus sp. VS04 (Vishnu et al., 2014) and Bacillus sp. (Parmar and Pandya, 2012).

These microbial amylases are now available commercially and they have almost completely replaced acid hydrolysis of starch in starch processing industry (Gupta et al., 2003) because of number of advantages such as specificity of the reaction, stability of the generated products, lower energy requirements and elimination of neutralization steps (Satyanarayana et al., 2005).

Amylases are useful in a broad range of industrial applications ranging from baking, brewing, fermentation, textile, paper and detergents industries (Singh et al., 2009). Due to the industrial importance of amylases, there is an ongoing interest in the isolation of new bacterial strains producing enzymes suitable for industrial applications such as alkaline amylases for the decrement industry and starch saccharifications (Ben-Ali et al., 1999).

The production of amylases has been found to be influenced by growth conditions and nutrients (Gupta et al., 2003). The present study was mainly focused on the production of amylase from microbial source isolated from soil and optimizing various parameters to enhance the amylase production.

\section{Materials and Methods}

\section{Samples collection}

For isolation of microorganisms producing amylase, soil samples were collected from different places like the vegetable and grain market of Hisar and Rohtak, Haryana. The bacteria were isolated by serial dilution and streak plate methods. The isolates were maintained on starch agar medium.

\section{Screening of isolates}

The bacterial colonies were grown on starch agar medium (SAM) plates. After appearance of bacterial colonies, plates were washed with sterilized distilled water and $10 \mathrm{ml}$ of lugols iodine (prepared by dissolving $1 \mathrm{~g}$ iodine and $2 \mathrm{~g}$ potassium iodide in $300 \mathrm{ml}$ distilled water) was poured in each plate. After 15 min, the Petri plates were washed with sterilized water to wash off the excess of dye. Formation of the clear zones of hydrolysis around the colonies showed the production of amylolytic enzymes. The isolates showing clear zones of hydrolysis on starch agar medium were further purified by streak plate method and tested for their capability to produce amylase.

\section{Identification of isolate}

The selected isolate was grown at $30^{\circ} \mathrm{C}$ for 2 days on starch agar media (SAM) slants. The slants were submitted to Institute of Microbial Technology (IMTECH, CSIR), Chandigarh for identification. It was identified as Bacillus cereus and was added to their collection centre MTCC with accession number MTCC 10205.

\section{Optimization of fermentation conditions for amylase production}

The fermentation conditions for amylase production were studied for different parameters. The experiments were carried out systematically in such a way that the parameters optimized in one experiments was maintained at its optimum level in the subsequent experiments. The different parameters that enhance the production of amylase were studied by taking one factor at a time. The parameters such as different media (Starch agar, Nutrient broth, Luria bertani and M9 minimal media); incubation period (6-48 $\mathrm{h})$; incubation temperature $\left(25-45^{\circ} \mathrm{C}\right)$; inoculum size (1-5\%); pH (5-7.5); carbon 
sources-2\% (fructose, amylose, amylopectin, sucrose, xylose, D-glucose, sorbital and corn starch) and nitrogen sources-1\% (tryptone, casein hydrolysate, beef extract, ammonium chloride, ammonium sulfate, ammonium nitrate and ammonium persulfate) of the medium.

\section{Extraction of enzyme}

After $36 \mathrm{~h}$ of growth at $35^{\circ} \mathrm{C}$, the modified starch agar medium broth was filtered through 4 layers of muslin cloth and centrifuged at $10,000 \mathrm{rpm}$ for $15 \mathrm{~min}$ at $4^{\circ} \mathrm{C}$ in refrigerated centrifuged. The supernatant was used to assay the enzyme activity.

\section{Enzyme assay}

The most common way to follow the amylase activity is to determine the reducing sugars. Amylase in the sample hydrolyzes the substrate and the amount of released reducing sugar is determined spectrophotometrically using dinitrosalicylic (DNS) acid (Miller, 1959). A standard curve of maltose ranging from 0 to $1000 \mu \mathrm{g} / \mathrm{ml}$ was constructed and then determined the released maltose in the samples from standard curve. One unit of amylase activity is defined as the amount of enzyme that liberates 1 nmole of maltose equivalent under the experimental conditions in $1 \mathrm{~min}$.

\section{Results and Discussion}

In order to achieve maximum amylase production by Bacillus cereus MTCC 10205, a proper combination of various cultural conditions and nutrients was established. One single independent culture variable was altered while others were maintained at a constant level and level of extracellular amylase production was monitored. The results of present study are presented and discussed under different headings as under:

\section{Effect of media on amylase production}

The media optimization is an important aspect to be considered in the development of fermentation technology. The isolate Bacillus cereus MTCC 10205 was grown on different media (Fig.1) and it was found that enzyme activity was maximum $(136.70 \mathrm{U})$ when grown in starch agar medium. Among other media, nutrient broth (NB) medium showed enzyme production (105.31 U), next to SAM while LB medium exhibited the minimum enzyme production (56.05 U).

\section{Effect of incubation period}

The effect of incubation period on amylase production was studied by growing the isolate in SAM over a period of $48 \mathrm{~h}$ and at a temperature $30^{\circ} \mathrm{C}$ in $\mathrm{BOD}$ incubator. The amylase activity was detected only after $6 \mathrm{~h}$ of incubation.

The results presented in figure 2 clearly demonstrate that maximum amylase production occurs after $36 \mathrm{~h}$ of incubation with the yield of $146.52 \mathrm{U}$. After 36h, decline in the activity was observed with a value of $141.43 \mathrm{U}$ after $42 \mathrm{~h}$ and $137.01 \mathrm{U}$ after $48 \mathrm{~h}$ of incubation.

\section{Effect of incubation temperature}

Temperature is a vital environmental factor which controls the growth and production of metabolites by microorganisms and this is usually varied from one organism to another. In order to find out suitable and optimum temperature of incubation for the isolate MTCC 10205, the culture was grown at different temperature ranging from 25 to $45^{\circ} \mathrm{C}$ under submerged conditions in SAM.

The results presented in figure 3 revealed that this isolate yielded maximum amylase at $35^{\circ} \mathrm{C}$ (157.96 U). 
Fig.1 Production of amylase by Bacillus cereus MTCC 10205 on different media

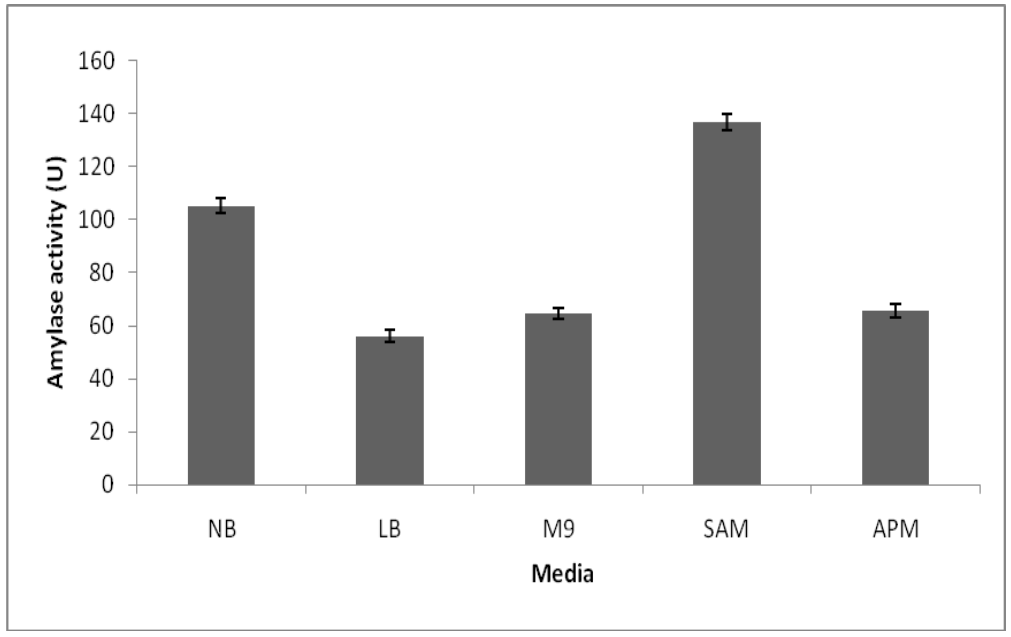

Fig.2 Effect of incubation time on amylase production by the isolate MTCC 10205

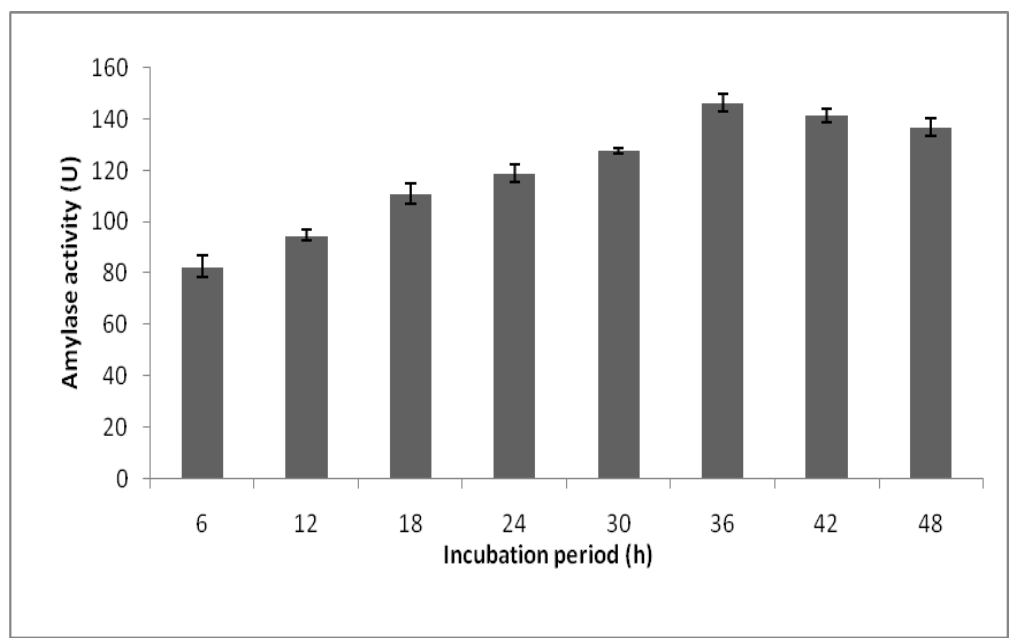

Fig.3 Effect of incubation temperature on amylase production by the isolate MTCC 10205

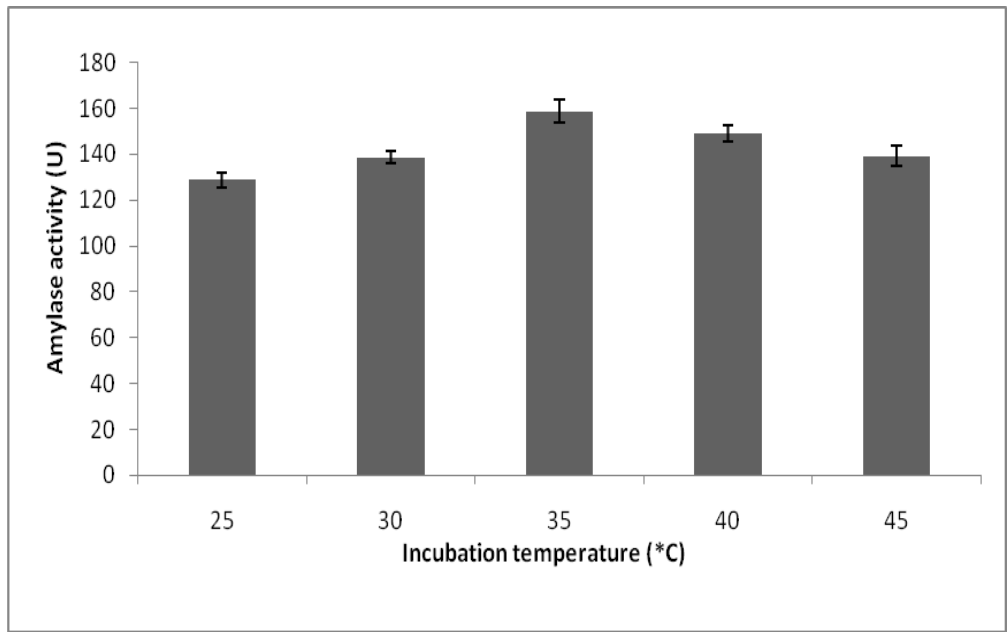


Fig.4 Effect of inoclum size on amylase production by the isolate MTCC 10205

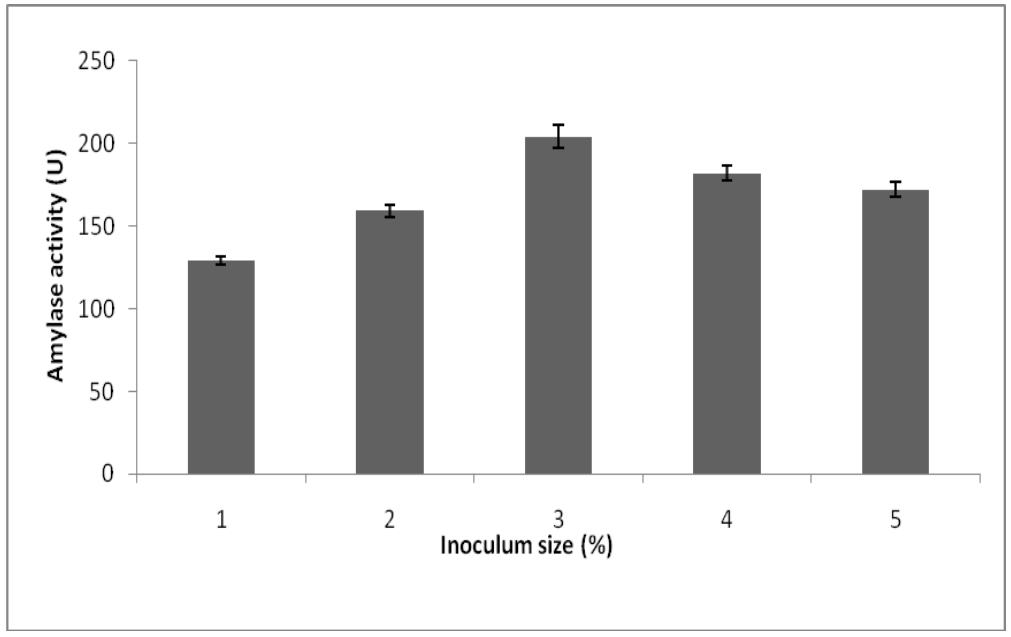

Fig.5 Effect of $\mathrm{pH}$ on amylase production by the isolate MTCC 10205

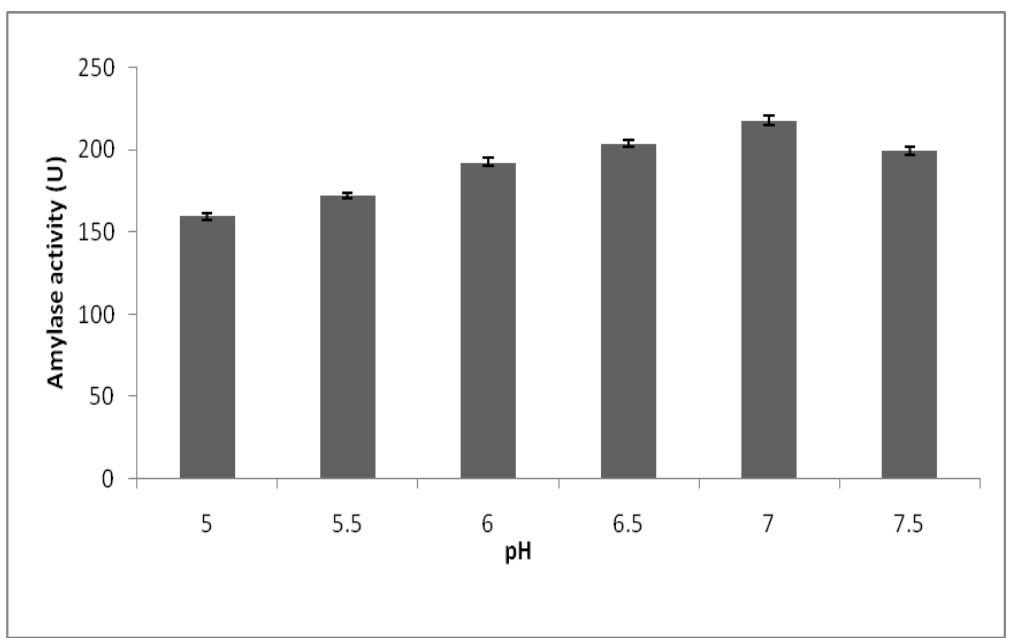

Fig.6 Effect of different carbon source on amylase production by the isolate MTCC 10205

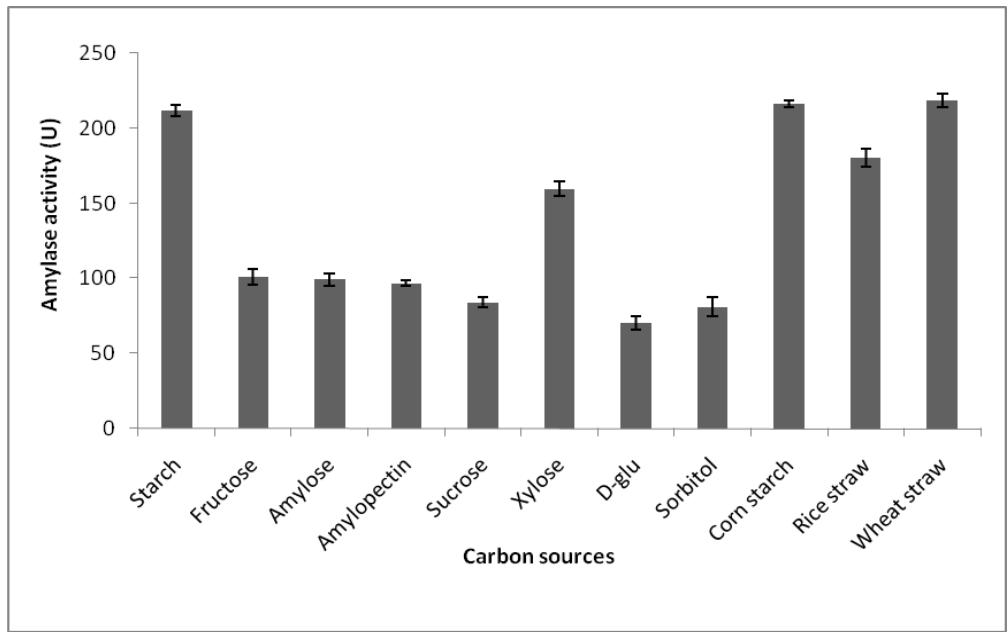


Fig.7 Effect of different nitrogen source on amylase production by the isolate MTCC 10205

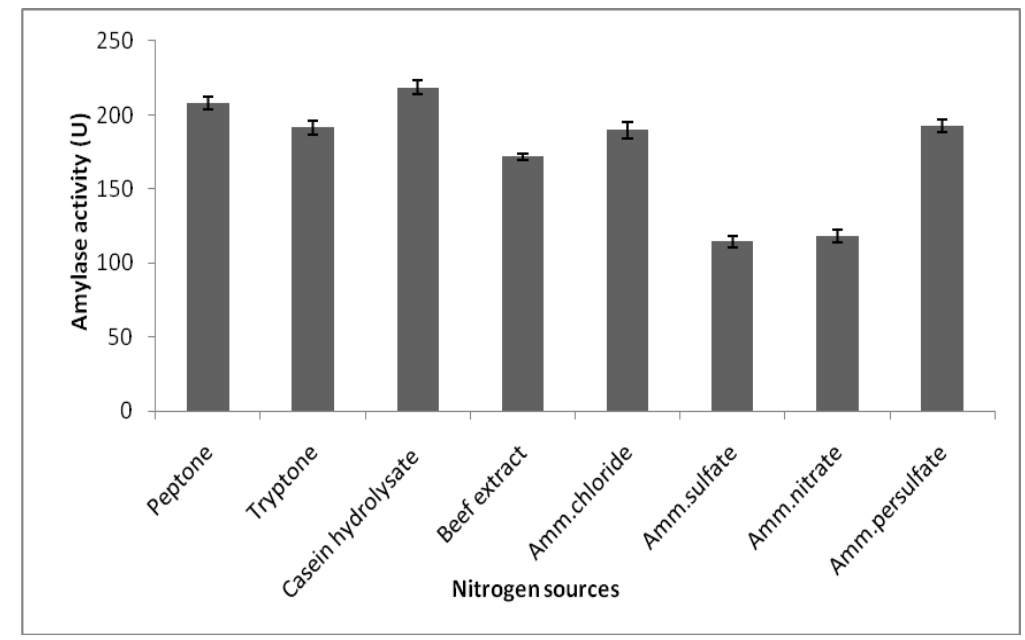

\section{Effect of inoculum size}

The amylase production from the isolate under study was studied at different inoculum size from $1 \%$ to $5 \%$. As shown in figure 4 . Maximum amylase production was recorded with 3 per cent inoculum (204.16 U). An inoculum concentration lower or higher than 3 per cent produced less amylase.

\section{Effect of Ph}

The influence of broth $\mathrm{pH}$ on amylase production by isolated bacterial strain was studied by growing the Bacillus cereus in SAM with $\mathrm{pH}$ varying from 5.0 to 7.5 in $\mathrm{SmF}$. As it is clear from results presented in figure 5, the maximum amylase production was observed at $\mathrm{pH} 7.0(203.71 \mathrm{U})$. On either side of the optimum $\mathrm{pH}$ (7.0) of the medium, the enzyme production decreased.

\section{Effect of carbon source}

To investigate the effect of various carbon sources on amylase production the present isolate was grown in different media containing starch, fructose, amylose, amylopectin, sucrose, xylose, D-glucose, sorbitol and corn starch as carbon source.
Medium containing starch as carbon source was taken as a reference having $211.63 \mathrm{U}$ of amylase activity.

Figure 6 shows that highest amylase production $(216.28 \mathrm{U})$ was obtained in medium containing corn starch. It was also observed that xylose also favoured amylase production with yield of $159.66 \mathrm{U}$, whereas $\mathrm{D}$-glucose inhibits the amylase production with yield of $70.43 \mathrm{U}$.

\section{Effect of nitrogen source}

The effect of various nitrogen sources on amylase production by the isolate, MTCC 10205 was studied by replacing peptone with alternative nitrogen sources. Among the different nitrogen sources, casein hydrolysate was found to be the best because it supported the maximum enzyme production $(218.54 \mathrm{U})$ (Fig. 7). Beef extract, ammonium chloride, ammonium per sulfate and tryptone also supported the enzyme production with yield of $171.77 \mathrm{U}, 189.67 \mathrm{U}, 192.50 \mathrm{U}$ and 191.36 $\mathrm{U}$, respectively, but not as efficient as peptone (207.78 U). Ammonium sulphate and ammonium nitrate proved to be the poorest.

The isolate Bacillus cereus MTCC 10205 was 
grown on different media and maximum enzyme activity was found to be $136.70 \mathrm{U}$ when grown in starch agar medium as compare to nutrient broth and LB medium. Similarly, Anto et al., (2006) reported the production of amylase from Bacillus cereus NY-14 and Bacillus cereus MTCC 1305 respectively. The effect of incubation period on amylase production was studied by growing the isolate in SAM medium. The maximum amylase production (146.52 U) was observed after $36 \mathrm{~h}$ of incubation period. These results are in accordance with Panda et al., (2008) who observed highest amylase production after $36 \mathrm{~h}$ of incubation of Streptomyces erumpens. Similarly, Bole et al., (2013) and Vishnu et al., (2014) reported the highest amylase production after $48 \mathrm{~h}$ and $72 \mathrm{~h}$ of incubation of Bacillus sp. and Bacillus sp. VS04, respectively. Likewise, the maximum amylase production was achieved at $35^{\circ} \mathrm{C}$ $(157.96 \mathrm{U})$ temperature by isolate MTCC 10205. Similar observations were also recorded in Bacillus sp. AS-1 (Qader et al., 2006) and Bacillus sp. (Bole et al., 2013).

The higher inoculum concentration increases the moisture content to a significant extent. This leads to a decrease in growth and enzyme production Baysal et al., (2003). Lower inoculum size results in a lower number of cells in the production medium. This requires a longer time to grow to an optimum number to utilize the substrate and to form the desired product. Maximum amylase production was recorded with 3 per cent inoculum. Similarly, Malhotra et al., (2000) and Vishnu et al., (2014) reported 2\% $(\mathrm{v} / \mathrm{v})$ inoculum size to be optimum for amylase production by $B$. thermooleovorans NP5 and Bacillus sp. VS04, respectively.

The $\mathrm{pH}$ is one of the important factors that determine the growth and morphology of microorganisms as they are sensitive to the concentration of hydrogen ions present in the medium (Sivaramakrishanan et al., 2006).
The maximum amylase production was observed at $\mathrm{pH}$ 7.0. Similar observations were recorded in Bacillus sp. at pH 7.0 (Parmar and Pandya 2012, Bole et al., 2013) and $B$. subtilis KIBGE-HAR (Riaz et al., 2009). The effect of various carbon and nitrogen sources on amylase production the present isolate was grown in different media. Medium containing starch as carbon source was taken as a reference having $211.63 \mathrm{U}$ of amylase activity. Starch is known to induce amylase production in different bacterial strains (ElBanna et al., 2007). Agricultural wastes are used for both liquid and solid fermentation to reduce cost of fermentation media. These wastes consist of carbon sources necessary for the growth and metabolisms of organisms. These sources include orange waste, pearl millet, potato, corn, tapioa, wheat and rice as flours Haq et al., 2005). Among the different nitrogen sources, casein hydrolysate was found to be the best because it supported the maximum enzyme production. Similar observations were recorded by Anto et al., (2006) in B. cereus MTCC 1305. In contrast, Qader et al., (2006) observed that the amylase production was maximum when yeast extract was used as a nitrogen source in Bacillus sp. AS-1

Therefore, the use of submerged fermentation for production of amylase using Bacillus cereus MTCC 10205 is an economical process and is very simple to apply. The maximum amylase production $(216.28 \mathrm{U})$ was obtained in starch agar medium containing corn starch as carbon source and casein hydrolysate was found to be the best nitrogen source with maximum enzyme production $(218.54 \mathrm{U})$ in $36 \mathrm{~h}$ at temperature $350 \mathrm{C}, \mathrm{pH}$ of 7.0 , and inoculum level of $3 \%$.

\section{Acknowledgements}

We thank the Head, Department of Biochemistry, College of Basic Sciences and Humanities, CCS HAU, Hisar for 
encouragement and technical support.

\section{References}

Aiyer PV (2005) Amylases and their applications. Afr J Biotechnol 4:15251529

Anto H, Trivedi U, Patel K (2006) Alphaamylase production by $B$. cereus MTCC 1305 using solid state fermentation. Food Technol Biotechnol 44:241-245

Anup A, Jayaraman G (2011) Detergent stable, halotolerant $\alpha$-amylase from Bacillus aquimaris VITP4 exhibits reversible unfolding. Int $\mathrm{J}$ Appl Biol Pharmaceutical Technol 2:366-376

Baysal Z, Uyar F, Ayteki C (2003) Production of $\alpha$ - amylase by thermo tolerant Bacillus subtilis in the presence of some carbon, nitrogen containing compounds and surfactants. Ann Microbiol 53:323328

Ben-Ali M, Mezghani M, Bejar S (1999) A thermostable $\alpha$-amylase producing maltohexose from a new isolated Bacillus sp. US 100: study of activity and molecular cloning of the corresponding agent. Enzyme Microbiol Technol 24:584-589

Bole S, Maji A, Dey A, Acharya A, Dubey S, Lal R (2013) Isolation, purification and characterization of amylase from airborne-bacteria. World J Pharmacy Pharmaceutical Sci 2:5878-5887

El-Banna TE, Ahmed A, Abd-Aziz AA, Abou-Dobara MI, Ibrahim RI (2007) Production and immobilization of $-\alpha-$ amylase from Bacillus subtilis. Pakistan J Biol Sci 10:2039-47

Gupta R, Gigars P, Mohapatra H, Goswami VK, Chauhan B (2003) Microbiol $\alpha$ amylases: a biotechnological perspective. Process Biochem 38:15991616

Haq I, Ashraf H, Qadeer MA, Iqbal J (2005) Pearl millet, a source of $-\alpha$ amylase production by $B$. licheniformis. Biores Technol 96:1201-1204

Malhotra R, Noorvez SM, Satyanarayana T (2000) Production and partial characterization of thermo stable and calcium independent $\alpha$-amylase of an extreme thermophile $B$. thermooleovorans NP54. Letters Appl Microbiol 31:378-384.

Miller GL (1959) Use of dinitrosalicylic acid reagent for determination of reducing sugar. Anal Chem 31:426-428

Panda SM, Swain MR, Kar S, Ray R, Montet D (2008) Statistical optimization of $\alpha$ amylase production by probiotic Lacto Bacillus plantarum MTCC 1407 in submerged fermentation. Polish J Microbiology 57:149-155

Parmar, D., Pandya, A. (2012) Characterization of amylase producing bacterial strain. Bull Environ Pharmacol Life Sci 1:42-47

Qader SA, Bano S, Aman A, Syed N, Azhar A (2006) Enhanced production and extracellular activity of commercially important amylolytic enzyme by a newly isolated strain of Bacillus sp. AS1. Turkey J Biochem 31:137-142

Rao DM, Swamy AVN, Ramakrishan GS (2006) Bioprocess technology strategies, production and purification of amylases: An overview. Internet $\mathbf{J}$ Genomics Proteomics 2:342-351

Riaz A, Qader SA, Anwar A, Iqbal S, Bano S (2009a) Production and characterization of thermostable $\alpha$-amylase from a newly isolated strain of $B$. subtilis KIBGE-HAR. The Internet $\mathrm{J}$ Microbiol $6: 1-17$

Satyanarayana T, Rao JLUM, Ezhilvannan M (2005) $\alpha$-amylases. In: Enzyme Microbial Technology. Pandey A, Soccol CR, Larroche C (ed), New Delhi, India. Asia tech Publishers Inc

Singh RK, Kumar S, Kumar S (2009) Production of $\alpha$-amylase from 
agricultural byproducts by Humicola lanuginosa in solid state fermentation. Curr Trend Biotechnol Pharmacy 3:172180

Sivaramakrishanan S, Gangadharan D, Nampoothrii MK, Soccol CR, Pandey A (2006) $\alpha$-amylase from microbial source-An overview on recent developments. Food Technol Biotechnol 44:173-184 Vishnu TS, Soniyamby AR, Praveesh BV, Hema TA (2014) Production and optimization of extracellular amylase from soil receiving kitchen waste isolate Bacillus sp. VS04. World Appl Sci J 29:961-967.

\section{How to cite this article:}

Nisha Kumari, Veena Jain, Kamla Malik and Sushil. 2017. Production and Optimization of Amylase from Bacillus cereus Using Submerged Fermentation. Int.J.Curr.Microbiol.App.Sci. 6(6): 263-271. doi: https://doi.org/10.20546/ijcmas.2017.606.032 